\title{
Response surface modelling and performance evaluation of solar dryer for drying of grapes
}

Aditya Arvind YADAV, Pravin A. PRABHU, Jaydeep S. BAGI

DOI: 10.30464/jmee.2021.5.2.157

Cite this article as:

Yadav A.A., Prabhu P.A., Bagi J.S. Response surface modelling and performance evaluation of solar dryer for drying of grapes. Journal of Mechanical and Energy Engineering, Vol. 5(45), No. 2, 2021, pp. 157-168.

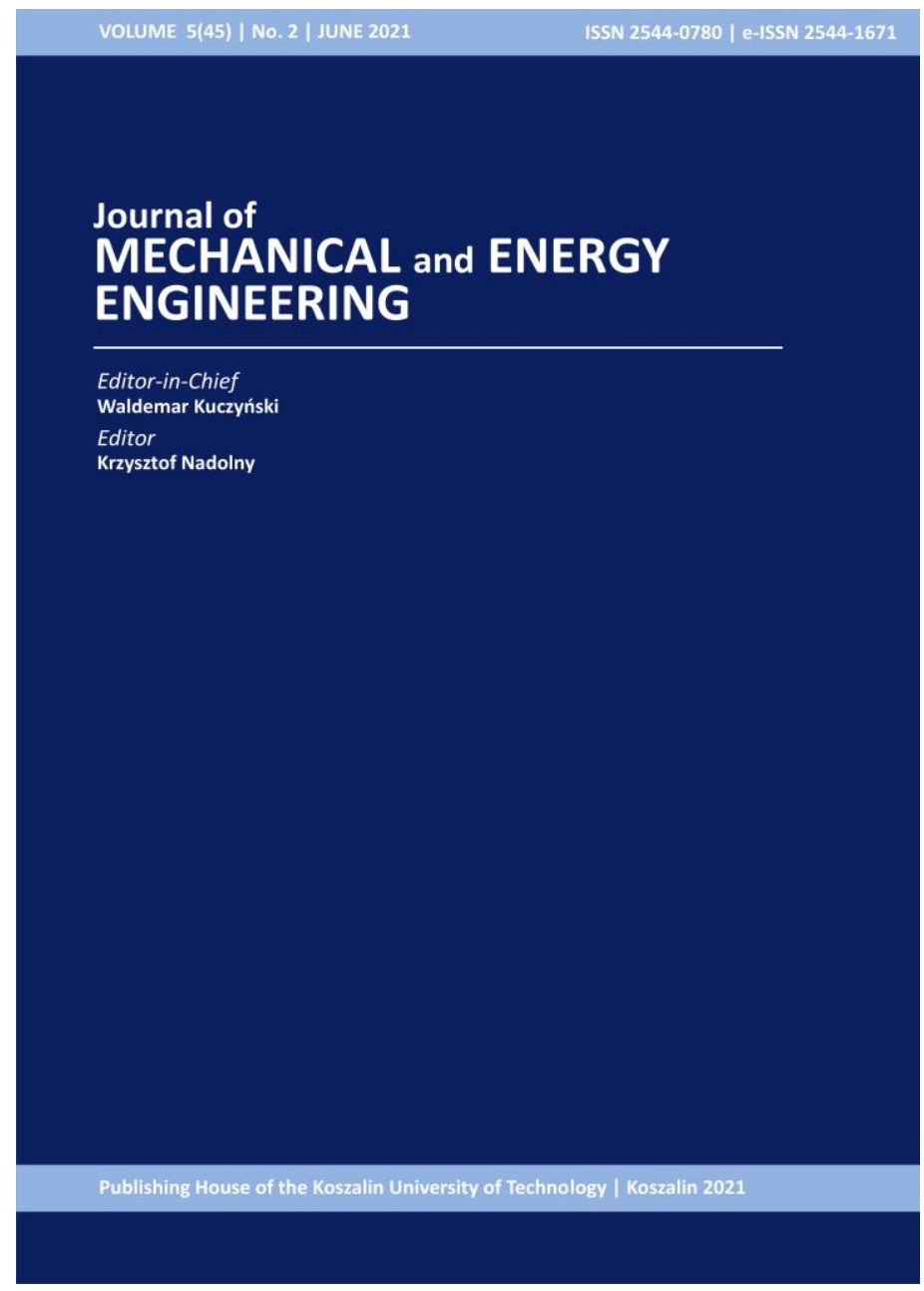

Journal of Mechanical and Energy

Engineering

Website: jmee.tu.koszalin.pl

ISSN (Print): 2544-0780

ISSN (Online): 2544-1671

Volume: 5(45)

Number: 2

Year: 2021

Pages: 157-168

Article Info:

Received 5 May 2021

Accepted 1 June 2021

\section{Open Access}

This article is distributed under the terms of the Creative Commons Attribution 4.0 (CC BY 4.0) International License (http://creativecommons.org/licenses/by/4.0/), which permits unrestricted use, distribution, and reproduction in any medium, provided you give appropriate credit to the original author(s) and the source, provide a link to the Creative Commons license, and indicate if changes were made. 


\title{
RESPONSE SURFACE MODELLING AND PERFORMANCE EVALUATION OF SOLAR DRYER FOR DRYING OF GRAPES
}

\author{
Aditya Arvind YADAV ${ }^{1 *}$, Pravin A. PRABHU ${ }^{2}$, Jaydeep S. BAGI ${ }^{3}$ \\ ${ }^{1}$ M. Tech (Energy Technology), Department of Technology, Shivaji University, India \\ e-mail: adiyadav821@gmail.com \\ ${ }^{2}$ Co-ordinator M. Tech (Energy Technology), Department of Technology, Shivaji University, India \\ ${ }^{3}$ Director of Department of Technology, Shivaji University, Kolhapur, Maharashtra State, India
}

(Received 5 May 2021, Accepted 1 June 2021)

\begin{abstract}
The current study focuses on the performance of the Solar Greenhouse Dryer for drying of grapes for raisin production in the Solar Dryer and Open sun condition in Western Maharashtra. The grape is also known as Vitis Vinifera, and it is a sub-tropical fruit with excess pulp content. The grapes are used as an immune booster as it contains various Phyto-chemicals which reduce various diseases. It is estimated that nearly $80 \%$ of grapes produced in India are exported to European countries. The Maharashtra state ranks first in the production of grapes; probably, Western Maharashtra produces nearly 800 thousand tons of grapes every year. The major wastage of grapes is due to a low sugar content, glossy appearance, shrinkage, excess water in the berry, scorching and size variations. Therefore, there is a need to preserve grapes by drying and production of raisins for a non-seasonal requirement. The experiment was conducted for drying of grapes in the Solar Greenhouse Dryer and Open Sun conditions from $1^{\text {st }}$ of April to $4^{\text {th }}$ of April for 48 hours. The initial weight of the grapes to be dried was 500 grams for both the Solar Greenhouse Dryer and Open Sun drying conditions. The experiment was conducted at Bahe, Borgaon, Tal-Walwa, DistSangli, Maharashtra, India located at $17.115^{\circ} \mathrm{N}$ and $74.33^{\circ} \mathrm{E}$. The experimental observations collected during the 'experimentation were set as input data for the Design of Experiments i.e., for Response Surface Modelling (RSM). The main aim of using DOE i.e., Response Surface Modelling, is to obtain an optimum region for drying of grapes in the Solar Greenhouse Dryer, from the Surface plot; a region of maxima and minima was obtained. The contour plot obtained during modelling resembles the optimum region of drying, the optimum region for drying grapes is 45 to $50^{\circ} \mathrm{C}$ respectively. The Moisture Removal Rate (MRR) for drying of grapes in the Solar Greenhouse Dryer and in the Open Sun drying is $73.6 \%$ and $57.2 \%$ respectively. The drying rate observed during the experiment has a better resemblance with simulated Response Surface Modelling.
\end{abstract}

Keywords: solar greenhouse dryer, drying, moisture removal, solar thermal energy, response surface methodology, design of experiments

\section{INTRODUCTION}

The solar drying technique is one of the oldest and traditional techniques used for the post-harvesting of crops, vegetables, and fruits. The main aim of the drying process is to decrease or release the moisture of the crop so that excess growth of microbes prevents any further losses. Open drying was implemented in many countries as the drying process is easily accessible for crops, but Open Sun drying affects the flavour of the product dried dried, its texture and colour because the temperature exceeds some limits [1]. Therefore, controlled drying is one of the advanced techniques that is used for drying crops under adequate temperature conditions to avoid flavour, texture, and colour losses during the drying process. The loss during Open Sun drying is sometimes unrecoverable. The texture of the product drieds dried affects the taste of the product. The weather conditions also affect the Open Sun drying phenomenon. An uneven climate change, uneven rainfall and uneven winds affect the product drieds 
dried to a greater extent. The quality and quantity of the final products dried affect it due to such uneven climatic conditions. The actual working of Open Sun drying is that the product dried is left under solar radiation for drying [2]. The solar energy incident onto the product dried heats the product and it finally releases the moisture content into the dry adjacent air thereby reducing the moisture of the product dried. The drying process is very useful in the agricultural context as it lowers post-harvest crop losses. It has been estimated that nearly $10 \%$ to $40 \%$ of the crops harvested every year face the problem of post-harvest losses [3].

In India, the climatic zones are divided into five types: namely, hot and dry, warm and humid, composite, temperate and cold respectively. According to the climatic zones, crops are grown in those particular areas, and there is a requirement for proper post-harvest technology that needs to be implemented considering the climatic zones [4]. Farmers in India rely most on the Open Sun drying for agricultural yields, but i some parts of the country, like cold zones, probably the Northern states of India, receive substantially lower amounts of solar radiation [4]. Therefore, there is a need for implementing a proper post-harvest technology that can suit the various climatic zones of India. The Solar Greenhouse Dryer (SGHD) is an active device that utilizes the incident solar radiation onto the surface of the dryer to allow heat gained by solar insolation to be trapped into the dryer, and it utilizes that heat energy to dry agricultural yield by using natural convection. The rural areas of India lack electricity due to excess load shedding, which leads to a major loss of agricultural yield in rural areas. The system designed for drying agricultural yield should be independent of grid electricity, thus natural convection is to be considered for drying. The objective of the present study is to determine the parameters of the Solar Greenhouse dryer that matche the local conditions i.e., the local environmental conditions of Western Maharashtra, and to evaluate the performance parameters like temperature and the moisture content of the product dried.[4]

The term: the greenhouse dryer is used for abuilding that is highly glazed with thermal conditioning for a desired range and it is used for cultivating crops, plants, vegetables, etc. The actual operation of a greenhouse is that short-wave radiation falling on the greenhouse is absorbed by the outer glazing material thereby heating the interior area of the greenhouse and providing ambient heat for plants and vegetable growth respectively. The heated space is retained within the enclosure of the greenhouse. This phenomenon is called the greenhouse effect. The important role is played during the greenhouse effect phenomenon by the atmosphere, insulating roofs, walls, etc. [4]
When solar radiation strikes the surface of the earth, some of it is absorbed by the earth's surface, while the rest is reflected in the form of infrared radiation. This infrared radiation emitted by the surface of the earth is then absorbed by various gases like $\mathrm{CO}_{2}$, methane, $\mathrm{NO}_{\mathrm{x}}$ and water vapour. This absorption of infrared radiation by the atmosphere and various gases like $\mathrm{CO}_{2}$, methane, $\mathrm{NO}_{\mathrm{x}}$ and vaporised water is called the greenhouse effect. The greenhouse effect helps in maintaining the temperature of the earth at ambient temperature; without the greenhouse effect, the earth's temperature would amount to $-18^{\circ} \mathrm{C}$ respectively $[5,6]$.

The various parameters considered during the designing of the solar greenhouse dryer are as follows.

1. Glazing Materials. The proper glazing materials allow maximum solar radiation to enter the greenhouse dryer. The heat loss from the glazing material should be as minimum as possible. The glazing material should possess maximum absorptivity and minimum reflexivity. The thin plastic foil absorbs direct and diffuse solar radiation.

2. Ventilation methods. Ventilation methods can be divided into free and forced ventilation. Free ventilation can be effectively used for solar drying as there is a lack of electricity in rural areas.

3. Solar Orientation. The Solar Greenhouse Dryer should be south-oriented to gain maximum solar radiation. The roof inclination should have a $23^{\circ}$ to $25^{\circ}$ roof angle to gain $90 \%$ of solar radiation. The north wall of the Solar Greenhouse Dryer is well insulated to avoid heat loss [4].

The current study aims to design and develop a static design for a solar greenhouse dryer for drying various agricultural yields in Western Maharashtra during sunshine and non-sunshine hours. The rural areas of Western Maharashtra, probably Sangli, Satara, Solapur and Kolhapur lack in terms of the use of electricity for agricultural yield i.e., post-harvest management [7]. The use of grid electricity is reduced because of uneven load shedding. Thus, to avoid various post-harvest losses in Western Maharashtra, there is a need for a device that can reduce the moisture content of agricultural yield without using grid electricity[7].

\section{METHODS}

The Maharashtra state ranks first in the production of grapes; probably, Western Maharashtra produces nearly 800 thousand tons of grapes every year. The districts like Sangli, Satara, Kolhapur have been tremendously affected by adverse climatic conditions every year. Climatic conditions like adverse rainfall or adverse fog affect the growth as well as the overall life of grapes. The major wastage of grapes is due to low sugar content, glossy appearance, mealy bugs, shrinkage, excess water in berry, scorching and size 
variation. Therefore, there is a need to preserve grapes by drying and making raisins for non-seasonal requirements.

The availability of electricity in rural areas of Sangli, Satara and Kolhapur varies over time and due to climatic conditions. These areas have to face excess load shedding; thus, it is not possible to use an airconditioned atmosphere to prevent post-harvest loss by every farmer as the cost incurred by the storage unit is higher. Thus, there should be a provision of proper drying technology that can be used by local farmers that is cost-effective and time efficient.

The conventional raising production process in Western Maharashtra starts from the mid of February to mid of April; during these months, the temperature in Western Maharashtra ranges from 40 to $45^{\circ} \mathrm{C}$ and has lower relative humidity i.e., 30 to $35 \%$. In the rural areas of Sangli, Satara and Kolhapur, grape drying shades are erected at the location where there is an absence of water bodies. Grape drying shades consist of a long iron-mesh platform on which grapes are spread in bunches and in layers. Before the bunches of grapes are laid on the drying mesh, they are initially given a pre-treatment process by dipping the grapes in a solution of ethyl oleate and potassium carbonate for 6 to 10 minutes for fast water loss from the berries. After the grapes are laid on a drying mesh, to obtain a good colour and avoid browning the grapes, ascorbic acid is spread over grapes. In some parts of Western Maharashtra, where the temperature and humidity fall below the average value, sulphur is burnt in presence of oxygen to produce sulphur dioxide. During sulphur burning, the racks are covered with curtails for several hours.

The major drawback with the conventional grape drying process is the use of various chemicals during the drying process such as ethyl oleate, potassium carbonate and sulphur, which affects human health after the consumption of raisins. The proposed Solar Greenhouse Dryer drying of grapes is totally free from any kind of chemicals; also, the time required for drying grapes in conventional system ranges from 15 to 20 days, whereas the Solar Greenhouse Dryer requires only four days respectively. Thus, the Solar Greenhouse Dryer is an eco-friendly and cost-effective solution for drying of grapes in rural settings.

The proposed Solar Greenhouse Dryer has a triangular roof with a vent on the roof side to allow air passage for ventilation. The Solar Greenhouse Dryer is manufactured initially with a Mild Steel square pipe and is covered with a thin plastic foil of $2 \mathrm{~mm}$ thickness, to allow the maximum solar gain during sunshine hours. The bottom surface of the Solar Greenhouse dryer is covered with a sandbar or course sediment for the heat gained from the sun to trap into the Solar Greenhouse Dryer. The roof of the Solar Greenhouse Dryer is provided with an inclination of $17^{\circ}$ i.e., the latitude of
Bahe Borgaon, Tal- Walwa, Dist- Sangli, Maharashtra, India, where the experiment was conducted. The overall dimensions of the Solar Greenhouse Dryer are as given in Table 1.

Tab. 1. Dimensions of CAD Model [7]

\begin{tabular}{ccc}
\hline Sr. no. & Specifications & Details, $\mathrm{mm}$ \\
\hline 1. & Length & 1000 \\
\hline 2. & Height & 400 \\
\hline 4. & Width & 600 \\
\hline
\end{tabular}

The drying tray provided for SGHD is inclined to the base surface to maximize the inclined solar radiations onto the dryer. The two-air inlet is provided along with the upper duct section for a free passage of air into the Solar Greenhouse Dryer. The drying tray is provided with a fine wire mesh for drying agricultural yield. The North wall of the Solar Greenhouse Dryer was insulated to avoid heat loss during the drying process. The drying process was performed using free convection, as in many rural areas there is loadshedding due to which electricity cannot be effectively used for drying phenomenon. The actual experimental setup is as shown in the Figure 1.

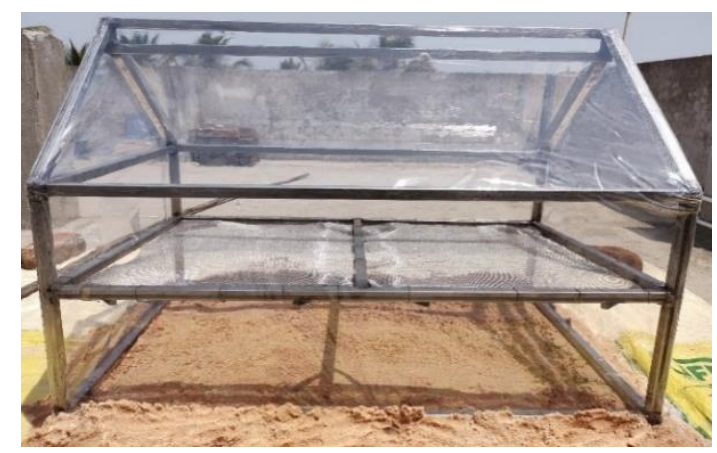

Fig. 1. Actual Experimental Setup of SGHD.

\section{EXPERIMENTAL METHODOLOGY}

The product used for the drying was grapes as it is abundantly available in the western Maharashtra region. Initially, 500 grams of fresh grapes harvested from the farm was used for drying in the Solar Greenhouse Dryer; the same amount of grapes was used for Open Sun drying. The grapes used for drying for raisin production were given heat treatment for 15 to 20 seconds and they were allowed to cool for 5 minutes respectively. The drying mechanism of grapes is as elaborated in the block diagram below (Fig. 2).

\section{MECHANISM OF DRYING}

The major heat transfer associated with the drying process of grapes is convection and radiation type of heat transfer. Initially, when solar radiation strikes the oof and the walls of the Solar Greenhouse dryer, the radiation type of heat transfer is observed i.e., heat energy 


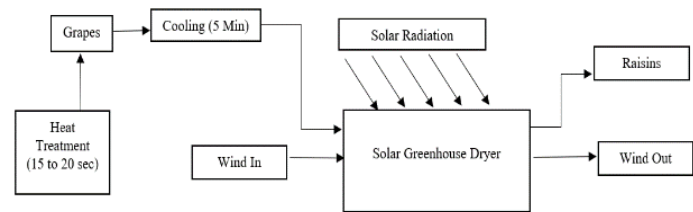

Fig. 2. Block diagram for drying of grapes.

from solar radiation has been transferred to the walls, the roof and the area enclosed by the dryer. The second mode of heat transfer observed is the convection type of heat transfer, when wind starts to flow inside the enclosed greenhouse dryer, heat energy gained by the walls and the roof area during radiation is transferred throughout the dryer equally. The combination of radiation and convection types of heat transfer continues after every cycle of radiation and convection heat transfer $[8,9]$. The product dried left on the drying net receives this combination of radiation and convection heat transfer, and water vapour inside the product is evaporated due to heat gained by radiation and convection currents.

\section{RESULTS}

The experiment was conducted from 7 am to $7 \mathrm{pm}$ from $6^{\text {th }}$ to $9^{\text {th }}$ of April 2020 at Bahe Borgaon, TalWalwa, Dist- Sangli, Maharashtra, India located at $17.115^{\circ} \mathrm{N}$ and $74.33^{\circ} \mathrm{E}$ respectively [10]. The drying of grapes was performed in the Open Sun and the Solar greenhouse Dryer under natural convection. The dryer was kept on a sand surface away from all kinds of shadows to allow maximum solar gain. The initial weight of the grapes to be dried in the Open Sun condition and the SGHD condition was 500 grams both respectively. The details of the drying of the grapes in the Solar Greenhouse Dryer vs. Open Sun drying are as elaborated in the figure below:

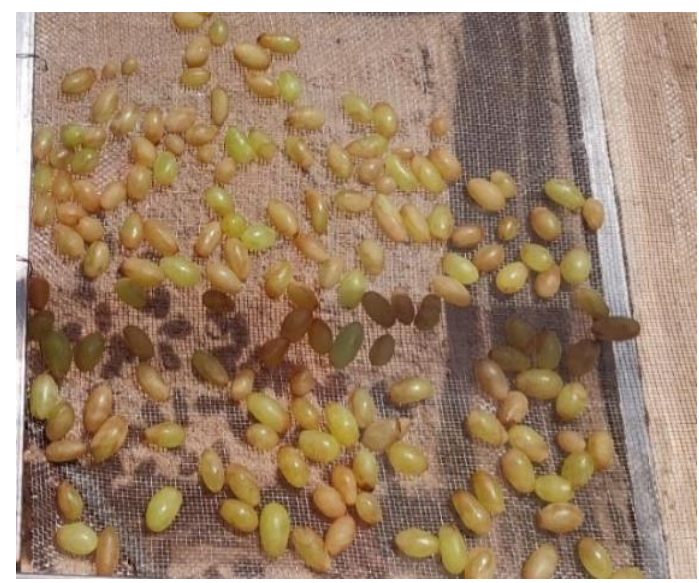

Fig. 3. Drying of grapes in SGHD

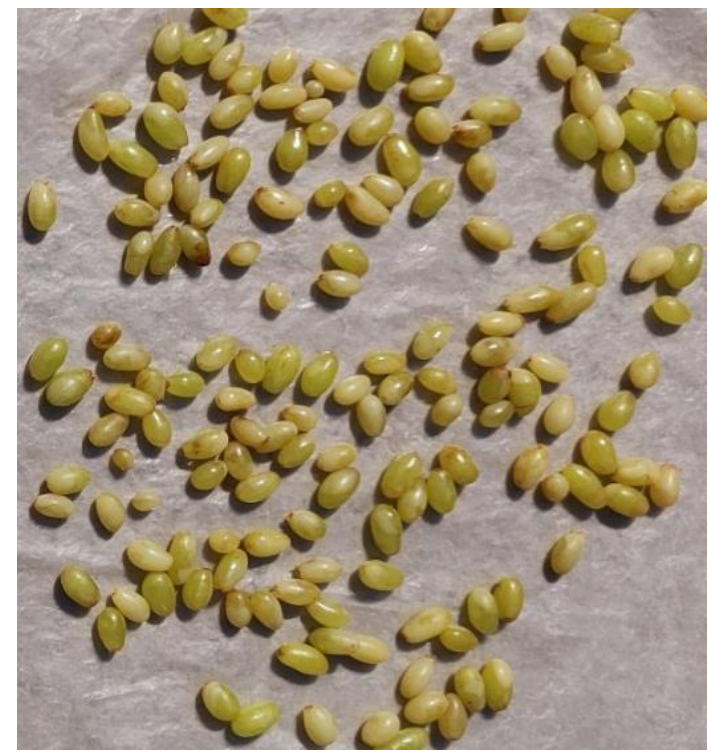

Fig. 4. Drying of grapes in Open sun condition

The total time required to dry the grapes was 48 hours. The details of the drying of grapes in the SGHD and Open Sun conditions is as described in Tab. 2.

The scatter plot for drying of grapes in Solar Greenhouse dryer is shown on Fig. 5 to 8.

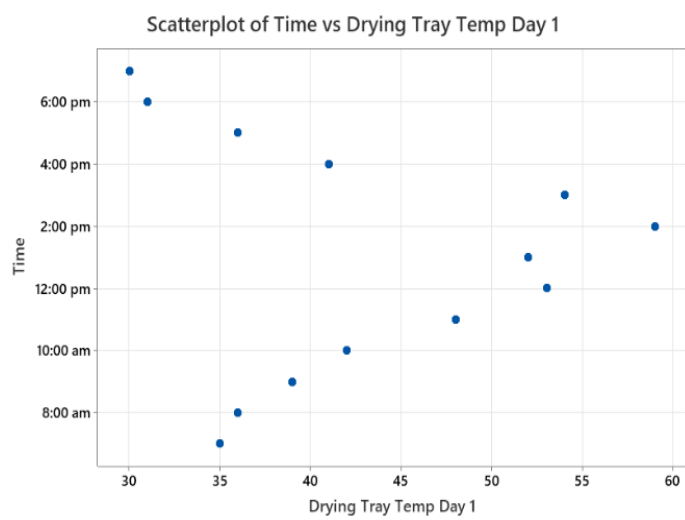

Fig. 5. Scatter plot for drying of grapes on Day 1

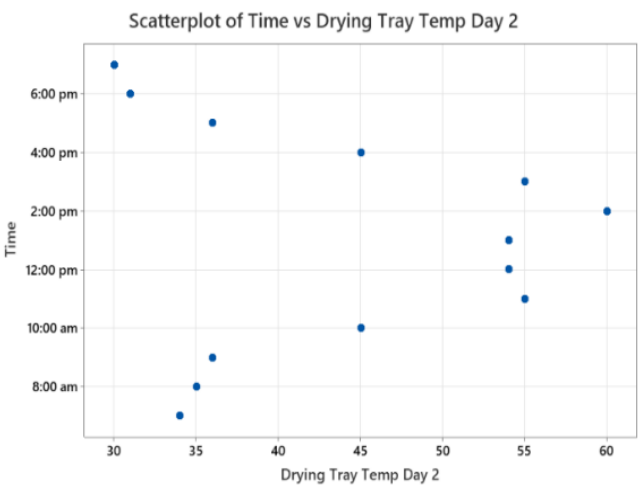

Fig. 6. Scatter plot for drying of grapes on Day 2 
Tab. 2. Experimental observations for drying of grapes

\begin{tabular}{|c|c|c|c|c|c|c|c|}
\hline $\begin{array}{l}\text { Sr. } \\
\text { no }\end{array}$ & Time & Day & $\begin{array}{l}\text { Wind } \\
\text { Speed } \\
(\mathrm{m} / \mathrm{s})\end{array}$ & $\begin{array}{l}\text { Solar radiation } \\
\qquad\left(\mathrm{W} / \mathrm{m}^{2}\right)\end{array}$ & $\begin{array}{c}\text { Temperature (Atmosphere) } \\
\left({ }^{\circ} \mathrm{C}\right)\end{array}$ & $\begin{array}{l}\text { Temp (SGHD) } \\
\left({ }^{\circ} \mathrm{C}\right)\end{array}$ & $\begin{array}{c}\text { Drying Tray Temp } \\
\left({ }^{\circ} \mathrm{C}\right)\end{array}$ \\
\hline \multirow[t]{4}{*}{1.} & 7:00 am & 1 & 0.10 & 58 & 25 & 30 & 35 \\
\hline & & 2 & 0.08 & 115 & 26 & 30 & 34 \\
\hline & & 3 & 0.35 & 218 & 20 & 24 & 29 \\
\hline & & 4 & 0.25 & 185 & 25 & 30 & 34 \\
\hline \multirow[t]{4}{*}{2.} & 8:00 am & 1 & 0.18 & 116 & 28 & 32 & 36 \\
\hline & & 2 & 0.15 & 425 & 25 & 32 & 35 \\
\hline & & 3 & 0.40 & 295 & 22 & 26 & 30 \\
\hline & & 4 & 0.30 & 618 & 28 & 35 & 36 \\
\hline \multirow[t]{4}{*}{3.} & 9:00 am & 1 & 0.30 & 570 & 26 & 35 & 39 \\
\hline & & 2 & 0.50 & 570 & 28 & 33 & 36 \\
\hline & & 3 & 0.50 & 370 & 24 & 29 & 31 \\
\hline & & 4 & 0.32 & 895 & 30 & 38 & 39 \\
\hline \multirow[t]{4}{*}{4.} & $10: 00 \mathrm{am}$ & 1 & 0.45 & 786 & 27 & 41 & 42 \\
\hline & & 2 & 0.40 & 845 & 38 & 45 & 45 \\
\hline & & 3 & 0.50 & 710 & 38 & 41 & 39 \\
\hline & & 4 & 0.30 & 901 & 40 & 48 & 46 \\
\hline \multirow[t]{4}{*}{5.} & $11: 00 \mathrm{am}$ & 1 & 0.75 & 938 & 23 & 48 & 48 \\
\hline & & 2 & 0.67 & 945 & 44 & 52 & 55 \\
\hline & & 3 & 0.30 & 915 & 45 & 53 & 53 \\
\hline & & 4 & 0.20 & 950 & 45 & 56 & 58 \\
\hline \multirow[t]{4}{*}{6.} & $12: 00 \mathrm{pm}$ & 1 & 0.50 & 980 & 40 & 52 & 53 \\
\hline & & 2 & 1.64 & 1025 & 46 & 56 & 54 \\
\hline & & 3 & 1.30 & 975 & 46 & 55 & 57 \\
\hline & & 4 & 0.15 & 970 & 48 & 57 & 59 \\
\hline \multirow[t]{4}{*}{7.} & $1: 00 \mathrm{pm}$ & 1 & 0.40 & 1002 & 43 & 53 & 52 \\
\hline & & 2 & 1.07 & 1012 & 47 & 55 & 54 \\
\hline & & 3 & 1.96 & 985 & 50 & 55 & 64 \\
\hline & & 4 & 1.20 & 950 & 50 & 58 & 57 \\
\hline \multirow[t]{4}{*}{8.} & $2: 00 \mathrm{pm}$ & 1 & 1.50 & 910 & 47 & 58 & 59 \\
\hline & & 2 & 1.10 & 880 & 51 & 52 & 60 \\
\hline & & 3 & 1.25 & 865 & 50 & 57 & 58 \\
\hline & & 4 & 0.50 & 920 & 50 & 61 & 60 \\
\hline \multirow[t]{4}{*}{9.} & $3: 00 \mathrm{pm}$ & 1 & 1.65 & 742 & 45 & 53 & 54 \\
\hline & & 2 & 1.60 & 820 & 50 & 52 & 55 \\
\hline & & 3 & 2.54 & 730 & 48 & 55 & 56 \\
\hline & & 4 & 0.20 & 875 & 48 & 54 & 56 \\
\hline \multirow[t]{4}{*}{10.} & $4: 00 \mathrm{pm}$ & 1 & 0.80 & 468 & 40 & 40 & 41 \\
\hline & & 2 & 1.95 & 802 & 43 & 46 & 45 \\
\hline & & 3 & 2.15 & 715 & 43 & 50 & 47 \\
\hline & & 4 & 0.15 & 701 & 47 & 53 & 51 \\
\hline \multirow[t]{4}{*}{11.} & $5: 00 \mathrm{pm}$ & 1 & 2.34 & 105 & 35 & 36 & 36 \\
\hline & & 2 & 2.60 & 540 & 35 & 36 & 36 \\
\hline & & 3 & 1.27 & 498 & 33 & 36 & 34 \\
\hline & & 4 & 0.10 & 480 & 40 & 42 & 40 \\
\hline
\end{tabular}




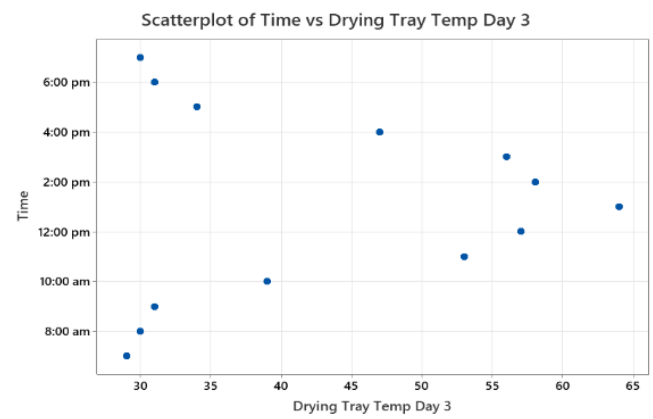

Fig. 7. Scatter plot for drying of grapes on Day 3

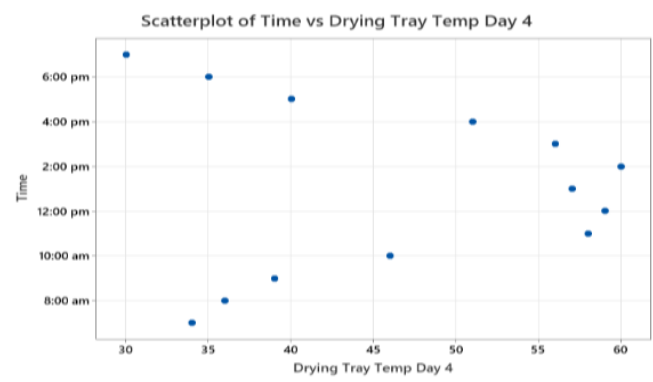

Fig. 8. Fig 8. Scatter plot for drying of grapes on Day 4

The experiment was conducted from $6^{\text {th }}$ of April 2021 to $9^{\text {th }}$ of April 2021 from 7 am to $7 \mathrm{pm}$. The scatter plots presented above resemble the heat gained by SGHD. The average maximum temperature gained by the Solar Dryer is between $55^{\circ}$ to $65^{\circ} \mathrm{C}$, and the minimum average temperature gained ranges between $30^{\circ}$ to $45^{\circ} \mathrm{C}$ respectively.

\section{RESULTS OF RESPONSE SURFACE METHODOLOGY}

The Mini Tab, a Statistical Simulation Software for the design of trials, Statistical Software was used to simulate the outcomes for the Response Surface Methodology (RSM). The main aim of using the Response Surface Methodology in drying grapes is to understand and to evaluate the topography of the response of the experimental observations, and finding the region of optimum response from the topography. The steps involved in the RSM simulation are as follows.

1. Initially, the Central Composite Design was selected as the number of the variables available as a continuous factor;

2. In the designs, the total number of runs selected during the simulation was 13 , the number of centre points and the value of alpha was set as a default, the default value for alpha was set to 1.414 respectively.

3. Then, for defining the cube points, the dependent variables i.e., solar radiation and wind speed was selected, and the low and high values of each set were entered.

The coded coefficients used during Response Surface Regression are given below in a Table 3. The Analysis of Variance (ANOVA) for drying of grapes in Solar Greenhouse Dryer is as follows (Tab. 4.).

Tab. 3. Coded coefficients in RSM

\begin{tabular}{|c|c|c|c|c|c|c|}
\hline Sr. No. & Terms & Coef & SE Coef & T-Value & P-Value & VIF \\
\hline \multirow[t]{4}{*}{1.} & Constant & 43.00 & 5.18 & 8.30 & 0.000 & - \\
\hline & & 37.40 & 3.30 & 11.35 & 0.000 & - \\
\hline & & 42.00 & 6.33 & 6.63 & 0.000 & - \\
\hline & & 52.40 & 4.38 & 11.96 & 0.000 & - \\
\hline \multirow[t]{4}{*}{2.} & Wind Speed & -2.38 & 4.10 & -0.58 & 0.579 & 1.00 \\
\hline & & 2.44 & 2.61 & 0.93 & 0.381 & 1.00 \\
\hline & & -4.07 & 5.01 & -0.81 & 0.443 & 1.00 \\
\hline & & -7.44 & 3.46 & -2.15 & 0.069 & 1.00 \\
\hline \multirow[t]{4}{*}{3.} & Solar Rad ${ }^{\mathrm{n}}$ & -1.29 & 4.10 & -0.32 & 0.762 & 1.00 \\
\hline & & -3.14 & 2.61 & -1.21 & 0.267 & 1.00 \\
\hline & & -1.29 & 5.01 & -0.26 & 0.804 & 1.00 \\
\hline & & 0.17 & 3.46 & 0.05 & 0.963 & 1.00 \\
\hline \multirow[t]{4}{*}{4.} & WS*SR & 1.19 & 4.39 & 0.27 & 0.795 & 1.02 \\
\hline & & 9.49 & 2.79 & 3.39 & 0.012 & 1.02 \\
\hline & & 1.06 & 5.37 & 0.20 & 0.849 & 1.02 \\
\hline & & -3.51 & 3.72 & -0.95 & 0.376 & 1.02 \\
\hline \multirow[t]{4}{*}{5.} & $\mathrm{SR} * \mathrm{SR}$ & -1.56 & 4.39 & -0.36 & 0.733 & 1.02 \\
\hline & & 0.99 & 2.79 & 0.35 & 0.734 & 1.02 \\
\hline & & 0.56 & 5.37 & 0.10 & 0.920 & 1.02 \\
\hline & & -6.51 & 3.72 & -1.75 & 0.123 & 1.02 \\
\hline \multirow[t]{4}{*}{6.} & WS*SR & -3.50 & 5.79 & -0.60 & 0.565 & 1.00 \\
\hline & & 7.75 & 3.69 & 2.10 & 0.074 & 1.00 \\
\hline & & 11.25 & 7.08 & 1.59 & 0.156 & 1.00 \\
\hline & & 0.25 & 4.90 & 0.05 & 0.961 & 1.00 \\
\hline
\end{tabular}


Tab. 4. Details of Analysis of Variance (ANOVA)

\begin{tabular}{|c|c|c|c|c|c|c|c|}
\hline & Source & Day & DF & Adj SS & Adj MS & F-Value & P-Value \\
\hline \multirow{4}{*}{1.} & \multirow{4}{*}{ Model } & 1 & 5 & 138.52 & 27.704 & 0.21 & 0.949 \\
\hline & & 2 & 5 & 993.34 & 198.669 & 3.66 & 0.060 \\
\hline & & 3 & 5 & 661.50 & 132.300 & 0.66 & 0.666 \\
\hline & & 4 & 5 & 788.02 & 157.604 & 1.64 & 0.266 \\
\hline \multirow{4}{*}{2.} & \multirow{4}{*}{ Linear } & 1 & 2 & 58.84 & 29.418 & 0.22 & 0.809 \\
\hline & & 2 & 2 & 126.48 & 63.238 & 1.16 & 0.366 \\
\hline & & 3 & 2 & 146.13 & 73.063 & 0.36 & 0.707 \\
\hline & & 4 & 2 & 442.54 & 221.269 & 2.30 & 0.170 \\
\hline \multirow{4}{*}{3.} & \multirow{4}{*}{ Wind Speed } & 1 & 1 & 45.46 & 45.463 & 0.34 & 0.579 \\
\hline & & 2 & 1 & 47.46 & 47.460 & 0.87 & 0.381 \\
\hline & & 3 & 1 & 132.83 & 132.829 & 0.66 & 0.443 \\
\hline & & 4 & 1 & 442.31 & 442.312 & 4.61 & 0.069 \\
\hline \multirow{4}{*}{4.} & \multirow{4}{*}{$\begin{array}{c}\text { Solar } \\
\text { Radiation }\end{array}$} & 1 & 1 & 13.37 & 13.373 & 0.10 & 0.762 \\
\hline & & 2 & 1 & 79.02 & 79.016 & 1.45 & 0.267 \\
\hline & & 3 & 1 & 13.30 & 13.297 & 0.07 & 0.804 \\
\hline & & 4 & 1 & 0.23 & 0.226 & 0.00 & 0.963 \\
\hline \multirow{4}{*}{5.} & \multirow{4}{*}{ Square } & 1 & 2 & 30.68 & 15.341 & 0.11 & 0.894 \\
\hline & & 2 & 2 & 626.62 & 313.309 & 5.77 & 0.033 \\
\hline & & 3 & 2 & 9.12 & 4.562 & 0.02 & 0.978 \\
\hline & & 4 & 2 & 345.23 & 172.616 & 1.80 & 0.234 \\
\hline \multirow{4}{*}{6.} & \multirow{4}{*}{$\begin{array}{c}\text { Wind } \\
\text { Speed*Wind } \\
\text { Speed }\end{array}$} & 1 & 1 & 9.81 & 9.810 & 0.07 & 0.795 \\
\hline & & 2 & 1 & 626.17 & 626.175 & 11.52 & 0.012 \\
\hline & & 3 & 1 & 7.85 & 7.853 & 0.04 & 0.849 \\
\hline & & 4 & 1 & 85.83 & 85.827 & 0.89 & 0.376 \\
\hline \multirow{4}{*}{7.} & \multirow{4}{*}{$\begin{array}{c}\text { Solar } \\
\text { Radiation*Sol } \\
\text { ar Radiation }\end{array}$} & 1 & 1 & 16.98 & 16.984 & 0.13 & 0.733 \\
\hline & & 2 & 1 & 6.78 & 6.784 & 0.12 & 0.734 \\
\hline & & 3 & 1 & 2.20 & 2.201 & 0.01 & 0.920 \\
\hline & & 4 & 1 & 295.04 & 295.045 & 3.07 & 0.123 \\
\hline \multirow{4}{*}{8.} & \multirow{4}{*}{$\begin{array}{c}\text { 2-Way } \\
\text { Interaction }\end{array}$} & 1 & 1 & 49.00 & 49.000 & 0.36 & 0.565 \\
\hline & & 2 & 1 & 240.25 & 240.250 & 4.42 & 0.074 \\
\hline & & 3 & 1 & 506.25 & 506.250 & 2.52 & 0.156 \\
\hline & & 4 & 1 & 0.25 & 0.250 & 0.00 & 0.961 \\
\hline \multirow{4}{*}{9.} & \multirow{4}{*}{$\begin{array}{c}\text { Wind } \\
\text { Speed*Solar } \\
\text { Radiation }\end{array}$} & 1 & 1 & 49.00 & 49.000 & 0.36 & 0.565 \\
\hline & & 2 & 1 & 240.25 & 240.250 & 4.42 & 0.074 \\
\hline & & 3 & 1 & 506.25 & 506.250 & 2.52 & 0.156 \\
\hline & & 4 & 1 & 0.25 & 0.250 & 0.00 & 0.961 \\
\hline \multirow{4}{*}{10.} & & 1 & 7 & 939.79 & 134.256 & & \\
\hline & Error & 2 & 7 & 380.35 & 54.336 & & \\
\hline & & 3 & 7 & 1404.50 & 200.643 & & \\
\hline & & 4 & 7 & 672.29 & 96.041 & & \\
\hline & & 1 & 3 & 439.79 & 146.596 & 1.17 & 0.424 \\
\hline 11. & Lack-of-Fit & 2 & 3 & 5.15 & 1.717 & 0.02 & 0.996 \\
\hline & & 3 & 3 & 290.50 & 96.833 & 0.35 & 0.794 \\
\hline & & 4 & 3 & 291.09 & 97.029 & 1.02 & 0.473 \\
\hline & & 1 & 4 & 500.00 & 125.000 & & \\
\hline 12. & Pure Error & 2 & 4 & 375.20 & 93.800 & & \\
\hline & & 3 & 4 & 1114.00 & 278.500 & & \\
\hline & & 4 & 4 & 381.20 & 95.300 & & \\
\hline & & 1 & 12 & 1078.31 & & & \\
\hline 13. & Total & 2 & 12 & 1373.69 & & & \\
\hline & & 3 & 12 & 2066.00 & & & \\
\hline & & 4 & 12 & 1460.31 & & & \\
\hline
\end{tabular}

The contour plots obtained from simulated Response Surface Modelling for the drying of grapes in the Solar Greenhouse Dryer are as shown in Figures 912. 
Contour Plot of Drying Tray Temp. vs Solar Radiation, Wind Speed

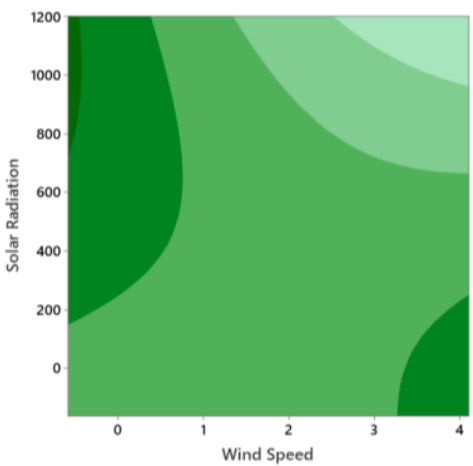

Fig. 9. Contour plot for day 1 drying

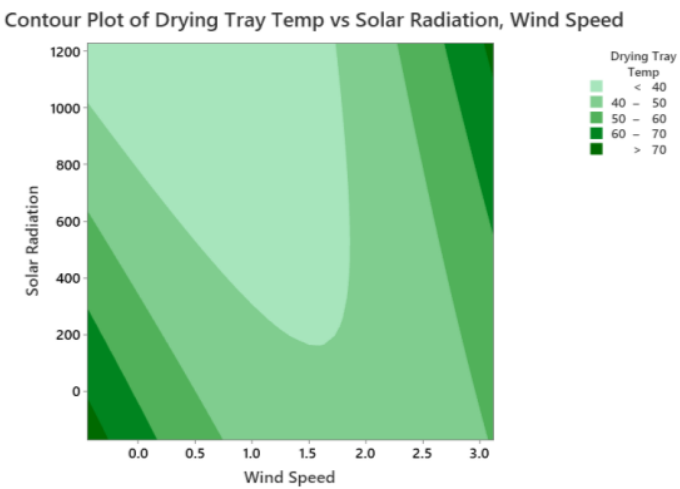

Fig. 10. Contour plot for day 2 drying

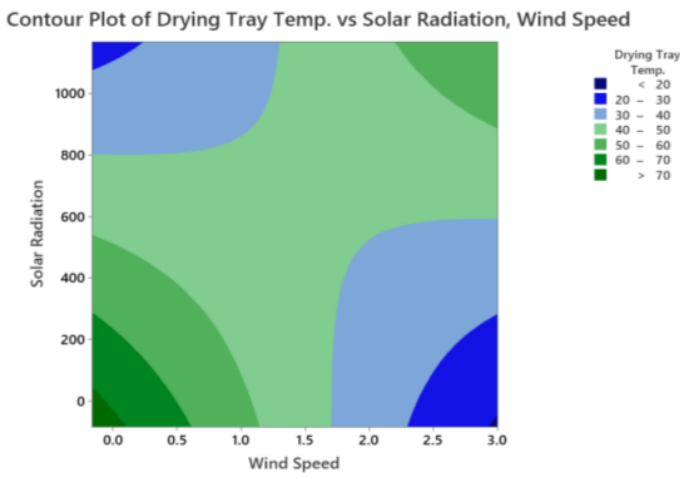

Fig. 11. Contour plot for day 3 drying

The contour plots obtained from Response Surface Modelling resemble the optimum drying temperature required for drying the grapes, i.e. $45^{\circ}$ to $50^{\circ} \mathrm{C}$. The maximum region under the curve for day 1 experimental observations ranges from $40^{\circ}$ to $45^{\circ} \mathrm{C}$ drying tray temperature, on day 2 the maximum area under the curve is $40^{\circ}$ to $50^{\circ} \mathrm{C}$; on day 3 the maximum area under the curve is between $40^{\circ}$ to $50^{\circ} \mathrm{C}$, and on day 4 maximum area under the curve lies between $45^{\circ}$ to $50^{\circ} \mathrm{C}$. Thus, the optimum temperature range required for the drying of the grapes in SGHD is in the range of $45^{\circ}$ to $50^{\circ} \mathrm{C}$ respectively.
Contour Plot of Drying Tray Temp vs Solar Radiation, Wind Speed
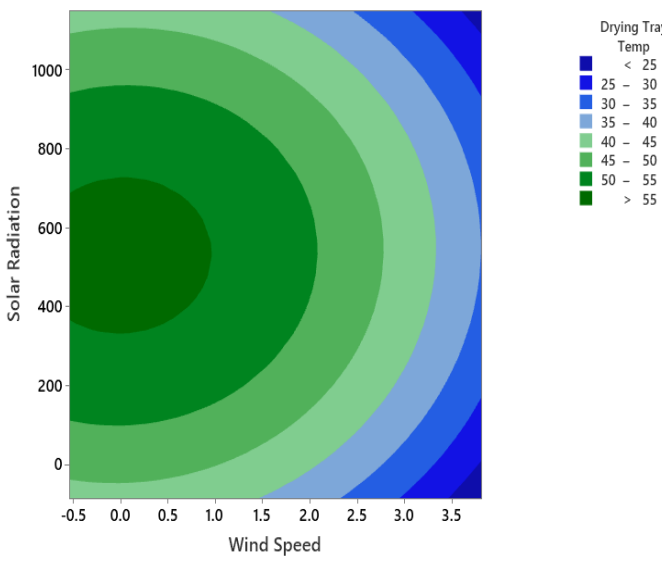

Fig. 12. Contour plot for day 4 drying

The contour plots enable one to set variable parameters like solar radiation or wind speed to an optimum range for proper drying of grapes. In the graphs above, the blue region indicates the region where the drying process is not adequate, whereas the light green colour indicates that the drying parameters are adequate, and the dark green region indicates that the drying parameters are optimum for the drying of the grapes. Hence, as per the experimental observations, the proper optimum region should be decided accordingly.

The Surface Plots obtained from simulated Response Surface Modelling for the drying of the grapes in the Solar Greenhouse Dryer is as shown in Figures 13-16.

Surface Plot of Drying Tray Temp. vs Solar Radiation, Wind Speed

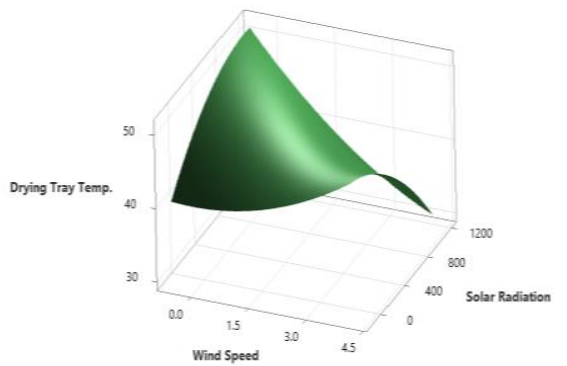

Fig. 13. Surface plot for day 1 drying

The surface plots obtained during the simulation of Response Surface Modelling on day 1 and day 4 have an optimum temperature distribution as the area under the curve is more for day 1 and 4 respectively. The Surface plots observed on day 2 and 3 have a satisfactory temperature distribution. 
Surface Plot of Drying Tray Temp vs Solar Radiation, Wind Speed

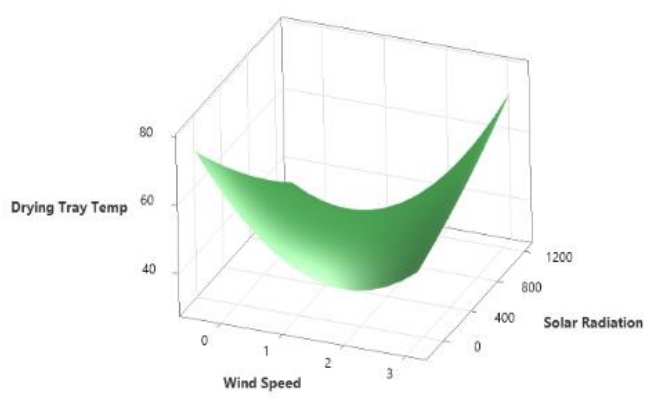

Fig. 14. Surface plot for day 2 drying

Surface Plot of Drying Tray Temp. vs Solar Radiation, Wind Speed

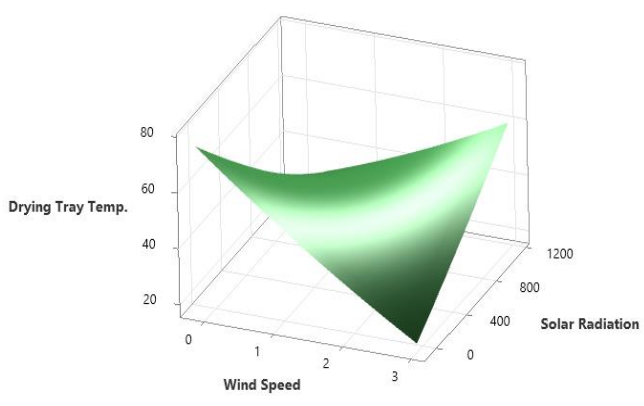

Fig. 15. Surface plot for day 3 drying

Surface Plot of Drying Tray Temp vs Solar Radiation, Wind Speed

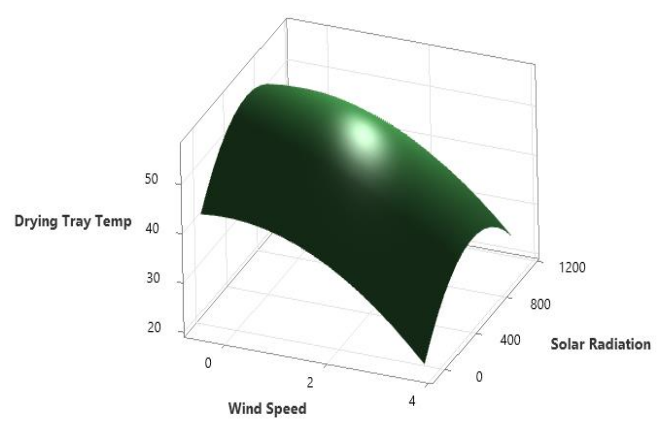

Fig. 16. Surface plot for day 4 drying

The surface plot is the $3 \mathrm{D}$ representation of the contour plot, the variable parameters like solar radiation, wind speed and drying tray temperature can combinedly be seen on the surface plot. The day 1 surface plot has ambient solar radiation and wind speed for the drying of the grapes. The day 2 representation of the surface plot is not adequate for the drying of the grapes, whereas day 3 has a good representation of variable parameters. The day 4 surface plot is optimum for the drying of the grapes, the surface plot obtained has optimum conditions for the drying of the grapes.

The surface plots obtained on day 1 and day 4 has an optimal solution as the solar radiation and wind speed required for the drying of the grapes were adequate. The surface plot curves obtained should be a dome-like structure, where exactly at the centre of the curve, the optimal region lies. The contour plots and the surface plots for day 1 and 4 have best optimal solution for the drying of the grapes.

\section{DISCUSSION}

The main aim of the drying of the grapes in SGHD is to prevent the grapes from various chemicals that are used during the convectional grape drying process. Further, the conventional system that is used in Western Maharashtra requires more than 15 days for the drying of the grapes. The Solar Greenhouse Dryer provides ambient conditions that are required for the drying of the grapes. The dried grapes raisins are free all kinds of chemicals, which is beneficial for human consumption. The simulated Response Surface Modelling for the drying of the grapes in SHGD has a better resemblance with experimental observations. The details of the weight reduction of the grapes are as elaborated in the Tab. 5 .

Tab. 5. Weight reduction in grapes after drying

\begin{tabular}{ccccc}
\hline & \multicolumn{2}{c}{ SGHD } & \multicolumn{2}{c}{ Open Sun } \\
\hline Day & $\begin{array}{c}\text { Initial } W t \\
(\mathrm{gms})\end{array}$ & $\begin{array}{c}\text { Final } W t \\
(\mathrm{gms})\end{array}$ & $\begin{array}{c}\text { Initial } W t \\
(\mathrm{gms})\end{array}$ & $\begin{array}{c}\text { Final } W t \\
(\mathrm{gms})\end{array}$ \\
\hline 1 & 500 & 298 & 500 & 348 \\
\hline 2 & 298 & 214 & 348 & 288 \\
\hline 3 & 214 & 164 & 288 & 248 \\
\hline 4 & 164 & 132 & 248 & 214 \\
\hline
\end{tabular}

Fig. 17. shows the details of weight reduction in SGHD and the Open Sun drying of grapes:

The initial weight of the grapes to be dried was 500 grams for both the Solar Greenhouse Dryer and Open Sun drying conditions. The day 1 weight reduction for SGHD and Open Sun drying was 298 grams and 348 grams; on day 2 the weight reduction for SGHD and Open Sun drying was 214 grams and 288 grams; on day 3 , the weight reduction for SGHD and Open Sun drying was 164 grams and 248 grams; whereas on day 4, the final weight reduction for SGHD and Open Sun drying was 132 grams and 214 grams respectively. The weight reduction percentage for the Solar Greenhouse Dryer is more as compared to that of Open Sun drying conditions. The weight reduction for solar greenhouse dryer is nearly $38.3 \%$ more as compared to that of Open Sun drying. 


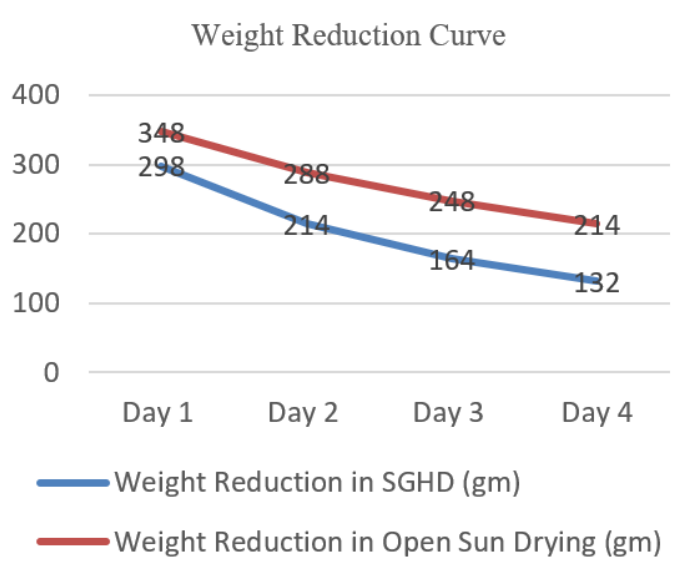

Fig. 17. Weight reduction curve

The Moisture Removal Rate (MRR) can be mathematically expressed:

$$
(M R R)=\frac{W i-W f}{W f} \times 100
$$

where $W i=$ initial weight of product, $W f=$ final weight of product.

The moisture removal rate $(\%)$ for SGHD and Open Sun drying for grapes is as given below in the Tab. 6 .

Tab. 6. MRR (\%) of grapes in SGHD and Open Sun.

\begin{tabular}{cccc}
\hline Sr. No & $\begin{array}{c}\text { Product to be } \\
\text { dried }\end{array}$ & $\begin{array}{c}\text { Moisture } \\
\text { Removal (\%) } \\
\text { in SGHD }\end{array}$ & $\begin{array}{c}\text { Moisture Removal } \\
\text { in (\%) Open Sun } \\
\text { Drying }\end{array}$ \\
\hline 1. & Grapes & $73.6 \%$ & $57.2 \%$ \\
\hline
\end{tabular}

The weight reduction rate for solar greenhouse dryer is $38.3 \%$ more as compared to that of Open Sun drying. The weight reduction directly affects the moisture removal rate of the grapes. The moisture removal rate for SGHD is $73.6 \%$ and for Open Sun drying, it is $57.2 \%$ respectively. Thus, the dryer is 16 $17 \%$ more efficient than Open Sun drying. The product obtained from SGHD is free from dust and other foreign matters. The product in SGHD is evenly dried as compared to Open Sun drying conditions.

The details of grapes after drying for 48 hours in Solar Greenhouse Dryer and Open Sun condition is as shown in Figure 18 and 19.

\section{LIMITATIONS}

The major factor affecting the drying time is wind speed and solar radiation; grapes in Western Maharashtra are harvested in the months of February to April respectively. Solar radiation in the month of April is high; but the wind speed is not up to an optimum level after $11 \mathrm{pm}$, thus the SGHD should be placed in an open

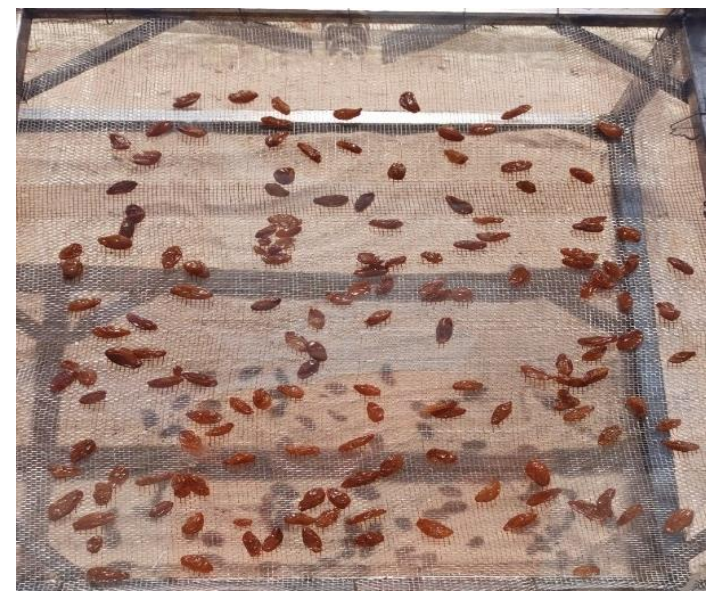

Fig. 18. Dried grapes (raisins) in SGHD

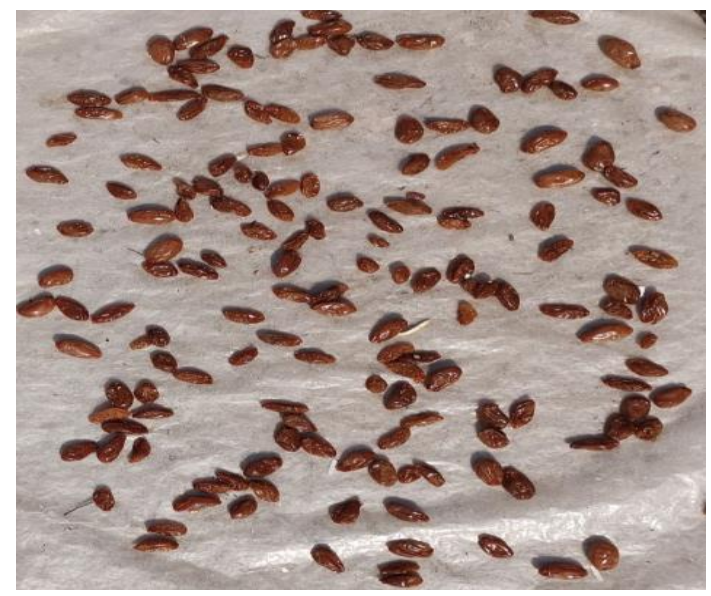

Fig. 19. Dried grapes (raisins) in Open Sun

environment so that air should surround the dryer for a maximum period. The wind speed during night time is higher in the month of April compared to that of daytime. The system can be equipped with a PV assisted fan or blower and can be used when the wind flow rate is very low. The current time required for the drying of grapes is 48 hours; the drying time can be reduced by properly loading the dryer. The SGHD can be effectively utilized in the months of March to May as solar radiation is abundantly available. The drying efficiency is directly linked with the amount of solar radiation falling on to the surface of the solar dryer. The Direct radiation can effectively dry the product but in some scenario due to cloud cover or any kind of shadow over the solar dryer, some part of agricultural yield is not properly dried. The solar dryer should be loaded with an optimum quantity of wet product, i.e., excess loading of solar dryer leads to uneven drying of the product.

\section{CONCLUSIONS}

The Solar Greenhouse Dryer is an effective way to prevent the agricultural yield from deterioration due to 
an excess growth of micro-organisms. The Solar Greenhouse Dryer provides the optimum temperature that is required for drying agricultural yields with a high moisture content. The initial weight of grapes to be dried for raisin production was 500 grams for both the Solar Greenhouse Dryer and the Open Sun drying conditions. The drying time for the raisin production process was 48 hours respectively. The experimental observations were taken from 1st of April 2021 to $4^{\text {th }}$ of April 2021 at Bahe Borgaon, Tal-Walwa, Dist- Sangli, Maharashtra, India located at $17.115^{\circ} \mathrm{N}$ and $74.33^{\circ} \mathrm{E}$. The grapes to be dried for raisin making were initially given heat treatment i.e., steam was allowed to pass over fresh farm harvested grapes for 5 to 10 seconds; after heat treatment, the grapes were quickly cooled and set for drying. The weight reduction of a heat treatment grapes after drying was 132 grams and 214 grams for SGHD and Open Sun drying conditions respectively. The Moisture Removal Rate (MRR) in per cent after drying is $73.6 \%$ for SGHD and $57.2 \%$ for Open Sun drying.

The experimental observations recorded during the drying process for both SGHD and Open Sun drying were used as input data for the Design of Experiments and Response Surface Modelling (RSM). The main goal of the Response Surface Modelling (RSM) method is to understand the varied topography of the experimental observations; another major goal of the topography obtained is to find a region of an optimum response from the set of observations and to move effectively along a path to get a maximum or minimum response. The results obtained from Response Surface Modelling are close to that of experimental observations. It is very clear from the results obtained from Response Surface Modelling that the optimum drying temperature for the drying of the grapes ranges from $45^{\circ} \mathrm{C}$ to $50^{\circ} \mathrm{C}$. The solar radiation required for optimum drying is in the range of $250 \mathrm{~W} / \mathrm{m}^{2}$ to 900 $\mathrm{W} / \mathrm{m}^{2}$, and a wind speed of $0.5 \mathrm{~m} / \mathrm{s}$ to $2.5 \mathrm{~m} / \mathrm{s}$ is required. The conventional raisin making process required nearly 10 to 15 days of drying, the proposed solar greenhouse drying is an effective technique for drying raisins and protecting the grapes from various types of biological degradation.

\section{Acknowledgments}

The Authors gratefully acknowledge the continuous support they have been receiving from the Department of Technology, Shivaji University, Kolhapur, Maharashtra, India for. No fund/grant is received for this research work.

\section{Conflicts of interest}

The Authors have no conflicts of interest to declare.

\section{References}

1. Vijayan S, Arjunan T. V., Anil Kumar. Fundamentals of Drying. Solar Drying Technology- Concept, Design, Testing and Modeling, Economics and Environment 2017; 3-38.

2. Labuza TP, McNally L, Gallagher D, Hawkes J, Hurtado F. Stability of intermediate moisture foods. 1. Lipid oxidation. Journal of Food Science 1972; 37(1):154-159.

3. Prakash O, Kumar A. Annual performance of modified greenhouse dryer under passive mode in no-load conditions. International Journal of Green Energy 2015; 12:1091-1099.

4. Yadav Aditya Arvind, Yadav Akshay Vijay, Bagi Jaydeep, Prabhu Pravin. Design of a Solar Modified Greenhouse Prototype. Journal of Science and Technology; 2021; 06(01); 118-125.

5. D. Jagadeesh, M. Vivekanandan, A. Natarajan et al., Experimental conditions to identify the ideal shape of dryer investigation of six shapes of solar greenhouse dryer in no load, Materials Today: Proceedings 2020; 1-9.

6. P. Pankaew , O. Aumporn, S. Janjai, S. Pattarapanitchai , M. Sangsan \& B.K. Bala. Performance of a large-scale greenhouse solar dryer integrated with phase change material thermal storage system for drying of chili. International Journal of Green Energy 2020; 1-12.

7. Yadav A A, Prabhu P. A., Bagi J. S. Experimental Performance and Response Surface Modelling of Solar Dryer for drying of bitter gourd in Western Maharashtra, India. Journal of Post-harvest Technology 2021; 9(3); 1-16.

8. Bekkioui N. Performance comparison and economic analysis of three solar dryer designs for wood using a numerical simulation. Renewable Energy 2021; 164:815-823.

9. Vivekanandan M, Periasamy K, Babu CD, Selvakumar G, Arivazhagan R. Experimental and CFD investigation of six shapes of solar greenhouse dryer in no load conditions to identify the ideal shape of dryer. Materials Today: Proceedings. 2020; 1-8.

10. Yadav A. A., Prabhu P. A., Bagi J. S. Numerical simulation and experimental validation of solar greenhouse dryer using finite element analysis for different roof shapes. Journal of Mechanical and Energy Engineering, Vol. 5(45),No. 1, 2021, pp. 69-80. 


\section{Biographical notes}

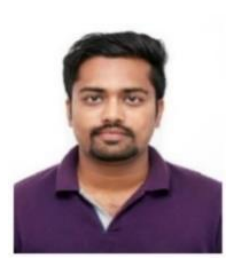

Aditya Arvind Yadav is M. Tech Research Scholar in Energy Technology at the Department of Technology, Shivaji University, Kolhapur, Maharashtra, India. His research work focuses on Solar Thermal Energy Storage and applications of Phase Change Materials in the solar dryer. He has published 19 research papers in various standard journals and conferences. His research metrics include a total of 9 citations and 2 h-index.

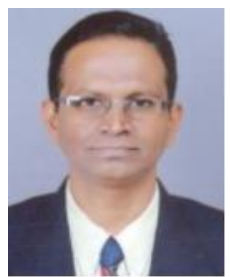

Pravin A. Prabhu is Assistant Professor and Co-Ordinator of M. Tech Energy Technology at the Department of Technology, Shivaji University, Kolhapur, Maharashtra, India. His research work focuses on Solar Thermal Energy Storage and applications of Phase Change Materials. He has published 07 research papers in various standard journals and conferences. His research metrics include a total of 36 citations and $2 \mathrm{~h}$-index.

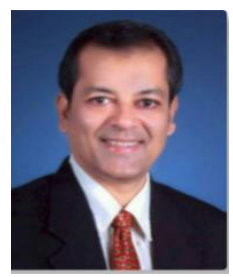

Jaydeep S. Bagi is a Professor and Director at the Department of Technology, Shivaji University, Kolhapur, Maharashtra, India. He has more than 50 research articles published in various reputed National and International Journals. His research metrics includes a total of 147 citations, 6 h-index and 5 i-10 index. 